\title{
Optimization of polyurethane lightweight aggregate with the addition of palm-based polyol
}

\author{
Kamarul Aini Mohd Sari ${ }^{1, a^{*}}$, Abdul Rahim M. Sani ${ }^{2, b}$, Sohif Mat ${ }^{3, c}$, \\ Khairiah Hj. Badri, d \\ ${ }^{1}$ Faculty of Engineering Technology, Universiti Tun Hussein Onn Malaysia, 86400 Batu Pahat, \\ Johor. \\ ${ }^{2}$ Vocational College of Batu Pahat, 83000 Batu Pahat, Johor. \\ 1,3Solar Energy Research Institute, Universiti Kebangsaan Malaysia, 45300 Bangi, Selangor. \\ ${ }^{4}$ Polymer Research Center, Universiti Kebangsaan Malaysia, 45300 Bangi, Selangor. \\ aaini@uthm.edu.my, barms772@yahoo.com, 'sohif@ukm.my, dkaybadri@ukm.edu.my
}

Keywords: lightweight aggregate, palm-based polyurethane, compressive strength, thermal conductivity.

\begin{abstract}
Lightweight aggregate for concrete was produced by utilizing palm-based polyurethane (PU) as a substantial material. New types of green PU were prepared by reacting palm kernel oil polyol (PKO-p) with 2, 4-methylene diphenyl diisocyanate (crude MDI). Six attempts on rigid PU were investigated to determine the reaction time, density, compressive strength, and thermal conductivity. An additional polyol showed high density between $200-300 \mathrm{~kg} / \mathrm{m} 3$. The compressive strength and thermal conductivity improved to $11.5 \mathrm{MPa}$ and $0.060 \mathrm{~W} / \mathrm{mK}$, respectively. As a conclusion, the results of palm-based PU showed excellent properties established the lightweight aggregate and insulation material in the concrete technology.
\end{abstract}

\section{Introduction}

Petrochemical resources have been used extensively worldwide in the chemical industry, particularly for expanded polystyrene (EPS) and polyurethane (PU) productions. These sources are now limited and have been depleting. They are also experiencing price instability. In the PU industry, polyols and isocyanates are two major ingredients used, and both are derived from petroleum. Vegetable oil and fat are alternative sources for polyols. Vegetable oils, like soybean oil, sunflower oil, palm oil, olive oil, and linseed oil, with a worldwide production of about 127 million tons in 2007, have been used mainly in food applications (76\%), while $19.5 \%$ account for technical applications, and $1.5 \%$ for other applications [1].

This study presents the usage of a natural, renewable, and sustainable material, namely palm kernel oil polyol (PKO-p), as a substitute to petroleum-based polyols in the PU industry. Badri [2] had successfully produced and developed a palm-based PU for wide applications, such as rigid foam, elastomer, coating, adhesive, and sealant. The PU system consists of PKO-p and 2, 4methylene diphenyl diisocyanate (crude MDI). Polyisocyanate acts as the polymerizing agent to the polyol. Thus, urethane and related forms are recognized as building block polymers [3].

Thehigh density PU foam able toachievehigher compressive strengthcompared to low-density PU. Hiroseetal. [4] reported thata goodspecimen of PU with lowdensityof $40-50 \mathrm{~kg} / \mathrm{m}^{3}$,subject of theapplication.MarkSonnenscheinetal. [5] and GonzalezGutierrezetal. [6]reviewed on waste PU with the density of $45-131 \mathrm{~kg} / \mathrm{m}^{3}$ and $68-72 \mathrm{~kg} / \mathrm{m}^{3}$, respectively. Then, Mounangaetal. [7] used fine aggregatedensity of $45 \mathrm{~kg} / \mathrm{m}^{3}$ with smaller size than/orequal to $10 \mathrm{mminlightweight} \mathrm{concrete.} \mathrm{On} \mathrm{the}$ other hand, Vaclaviketal.[8] investigated the effect ofthermalmodification ofmortarwith30$50 \mathrm{~kg} / \mathrm{m}^{3}$ density PU wasteas filler.

The purpose of this study was to determine the PU optimum proportion with additional PKO-p by volume, where MDI was kept constant. The properties of palm-based PU were also investigated, such as density, compressive strength, and thermal conductivity. 


\section{Experimental Study}

Materials. The PKO-p was supplied by UKM Technology SdnBhd through Badri's[9] pilot plant at MPOB Bangi Lama, Selangor, Malaysia. The PKO-p was synthesized by polyesterification and a polycondensation process [2]. The chemical used for the prepolymerization of PU foam was crude MDI (2,4-methylene diphenyldiisocyanate) from Cosmopolyurethane (M) Sdn Bhd, Port Klang, Malaysia.

Mix Proportions. Six ratios of PU were studied with sample A as the control. The other samples were mixed with an additional $20 \%$ of PKO-p. The mixture was stirred using a mechanical stirrer at $1000 \mathrm{rpm}$ for $10 \mathrm{~s}$. The mixture was then poured into a screw-tight mould, and was allowed to cure for $10 \mathrm{~min}$. The ratio of PKO-p resin to MDI was optimized prior to identifying the density and the stage of reaction. During the polymerization, the reaction time; cream time (CT), rise time (RT), and hardening time (HT) [3], were observed and recorded. Once demoulded, the PU foam was left to condition at room temperature for $16 \mathrm{~h}$ before further characterizations, such as density, compressive strength, and thermal conductivity were looked into.

\section{Characterization}

The foam density was determined following BS4370: Part 1: 1988 Method 2 by applying the equation of mass, $\mathrm{kg}$ divided by volume, $\mathrm{m}^{3}$. Foam samples were prepared via moulding technique into cubes of $50 \mathrm{~mm} \times 50 \mathrm{~mm} \times 50 \mathrm{~mm}$ in dimension. Three samples were used and were carefully weighed using an analytical balance.

The compression test for PU was conducted according to BS 4370: Part 1: 1988: Method 3. The samples were cut to the dimension of $50 \mathrm{~mm} \times 50 \mathrm{~mm} \times 50 \mathrm{~mm}$. The test was carried out using Instron Universal Testing Machine model 5566 at a cross-head speed of $50 \mathrm{~mm} / \mathrm{min}$ until the thickness was reduced to $10 \%$ of its original thickness. The compressive stress was recorded as the average for five specimens.

The thermal conductivity was conducted using theHeat Flow Meter HFM 436 Lambda, following ASTM C518. The samples of rigid PU foam were prepared via moulding technique using a thick plate of $300 \mathrm{~mm} \times 300 \mathrm{~mm} \times 25 \mathrm{~mm}$ and analyzed at the temperature of $20^{\circ} \mathrm{C}$.

\section{Results and Discussion}

Reaction time.Table 1 shows the data that determined the optimal parameters in the production of rigid PU. The optimization was done by accessing PKO-up, while MDI was maintained. Each sample was increased by $20 \%$ PKO-p.A total ofsixexperiments were carried out, with theaddition ofPKO-p. From the experiments, onlysamplesA,B, andCperformed complete PU in rigid foam. Meanwhile, samples D, E, and F were incomplete as the soft segment exceeded the hard segment. From the observation, the mixture formed a long chain of polyol, viscous, and sticky form. Therefore, nohardened timewas recorded.

Table 1 Optimization of PU by varying PKO-p

\begin{tabular}{|c|c|c|c|c|c|}
\hline \multirow[t]{2}{*}{ Sample } & \multicolumn{2}{|c|}{ PU ratio } & \multirow{2}{*}{$\begin{array}{l}\text { CT } \\
\text { (s) }\end{array}$} & \multirow{2}{*}{$\begin{array}{l}\text { RT } \\
\text { (s) }\end{array}$} & \multirow{2}{*}{$\begin{array}{l}\text { HT } \\
\text { (s) }\end{array}$} \\
\hline & PKO-p & MDI & & & \\
\hline A & 50.0 & 50.0 & 70 & 86 & 240 \\
\hline B & 54.5 & 45.4 & 64 & 99 & 330 \\
\hline $\mathrm{C}$ & 58.3 & 41.6 & 62 & 102 & 483 \\
\hline D & 61.5 & 38.5 & 63 & 96 & - \\
\hline E & 64.3 & 35.7 & 65 & 90 & - \\
\hline $\mathrm{F}$ & 66.6 & 33.3 & 66 & 100 & - \\
\hline
\end{tabular}

* CT: Cream time, RT: Rise time, HT: Hardened time

The reaction time for all the samples was relatively extensive. After stirring for $10 \mathrm{~s}$, the results showed that the creamtimeandrise time were almost60 sand100 s, respectively. The time process 
ofpolymerization was influenced bya triggering substanceused in the mixtures[10]. Generally, in the production of industrial PU, blowing agents, surfactant, and catalyst have been used.

Density.PUbased onpalm kernel oil (PKO)hadhigher densitycompared to PU in theindustry (40$\left.60 \mathrm{~kg} / \mathrm{m}^{3}\right)$. The densitywasbetween $200 \mathrm{~kg} / \mathrm{m}^{3}$ to $400 \mathrm{~kg} / \mathrm{m}^{3}$, depending on the materialscomposition. This density isclassified as high-densityrigid PU [10].Table2 showsthe significant modifications of densityforthree ratiosof PU. The density of control PU foam was $206 \mathrm{~kg} / \mathrm{m}^{3}$. With the addition of $20 \%$ PKO-pin theMDI, the densitywas increased up to $9.2 \%$. The increasewasdue to the increasedpolyolcrosslinkthat causedlongrangelinkages[2]. The density of PUis interconnectedwiththe compressionstrength and thermal conductivity [11].

Table 2 Properties of rigid PU

\begin{tabular}{cccc}
\hline Sample & $\begin{array}{c}\text { Density } \\
\left(\mathrm{kg} / \mathrm{m}^{3}\right)\end{array}$ & $\begin{array}{c}\text { Compressive strength } \\
(\mathrm{MPa})\end{array}$ & $\begin{array}{c}\text { Thermal conductivity } \\
(\mathrm{W} / \mathrm{mK})\end{array}$ \\
\hline $\mathrm{A}$ & 206 & 7.0 & 0.052 \\
$\mathrm{~B}$ & 225 & 9.3 & 0.053 \\
$\mathrm{C}$ & 266 & 11.5 & 0.062 \\
\hline
\end{tabular}

Compressive strength. The compressive strength of PU was proportional tothe density, as seen inFig.1. Densityis a key factor that influences the compressive strength. Higher density performs higher compressive strength [12]. The addition ofPKO-pincreased the compressive strength of $7 \mathrm{MPa}$ (sampleA)to $11.5 \mathrm{MPa}$ (sampleC). The compressive strength ofrigid PU was increasedup to $39.1 \%$. The modificationexisted due to thepresence ofsoftandhardsegmentsin the PU. Hence, moresoftsegments and cross linking wereproducedby increased addition of PKO-p. The hardsegment from the MDIcreated short linkages, and loose and brittlecross-bonding between the materials. Therefore, the compression strength was lower.

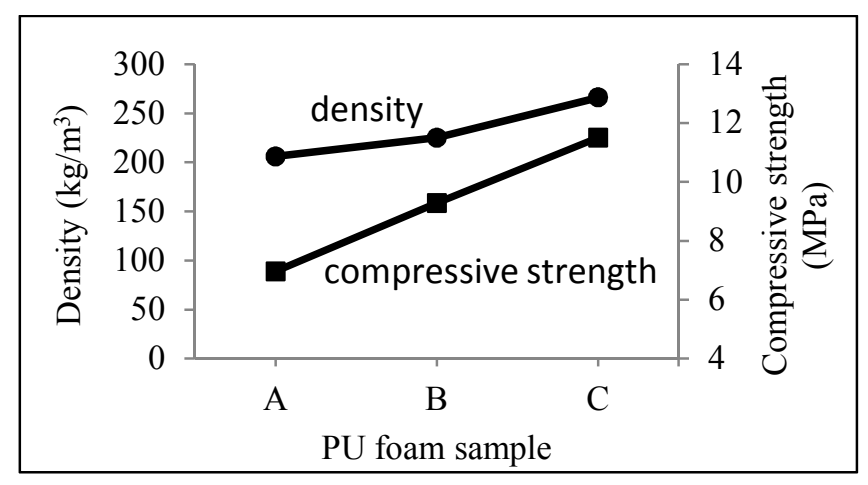

Fig. 1 The effects of density and compressive strength on PU foam sample.

Thermal conductivity. The highdensity of rigid PU developed high thermalconductivityvalue[13]. Fig.2 shows the effectsof palm-based PU on thermal conductivity for samples A, B, and C. A Heat Flow Meter was used to set the temperature at $20^{\circ} \mathrm{C}$. The graph shows that with the increase in the amountof PKO-p, higherthermal conductivity was achieved in accordance with thedensity. SampleA (density $206 \mathrm{~kg} / \mathrm{m}^{3}$ ) indicated thelowestthermal conductivityof $0.0518 \mathrm{~W} / \mathrm{mK}$. Therefore, with the addition of $20 \%$ of PKO-p to samples B and C, thevaluesincreased to $0.0533 \mathrm{~W} / \mathrm{mK}$ and $0.0619 \mathrm{~W} / \mathrm{mK}$, respectively. 


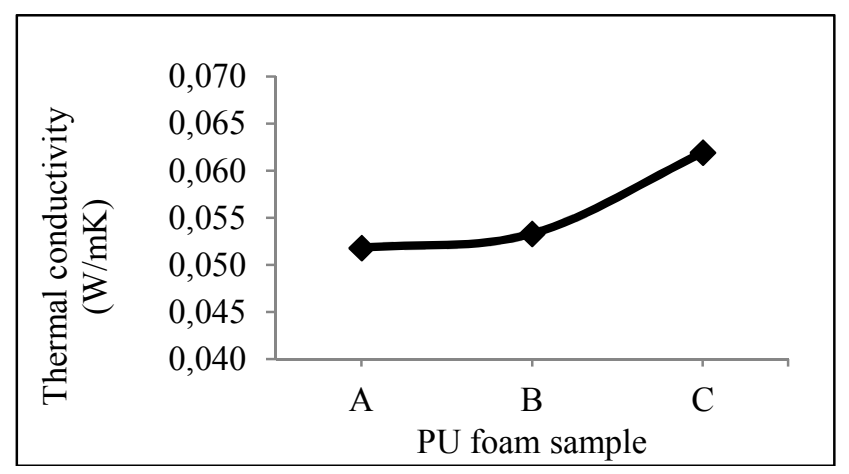

Fig. 2 The effects of thermal conductivity on palm-based PU at $20^{\circ} \mathrm{C}$

A PU rigid form has over90\% closed cells andis classified to have a verylowthermal conductivityandhigh compressive strength. The industrial PU (density of $30-100 \mathrm{~kg} / \mathrm{m}^{3}$ ) produced thermal conductivitybetween 0.024 and $0.030 \mathrm{~W} / \mathrm{mK}$, and compressive strength of $100-150 \mathrm{kPa}$ at $10 \%$ disability [14]. Lowerthermal conductivity value implemented better thermal properties. Badri[2] conducted a study on palm-based PU with a density of $40-60 \mathrm{~kg} / \mathrm{m}^{3}$ and it attained lowthermal conductivity; $0.025 \mathrm{~W} / \mathrm{mK}$.Although the thermal conductivityof rigid PU had been relatively higher compared tothe industrial PU,nevertheless the compressivestrength waspractical aslightweightaggregate.Thus, PU with compressivestrengthpropertiesandgoodthermal conductivity is suitable to be implementedas aninsulated lightweightaggregate.

\section{Conclusion}

The optimal proportion of new lightweight aggregate using natural-based PU was sample A with the ratio of 1:1 (PKO-p:MDI). By additional percentage of PKO-p, contributes to a higher k-value, indicating an excellent thermal insulation properties. Besides, the palm-based lightweight aggregate portrayed excellent properties of compressive strength $(11.5 \mathrm{MPa})$ and thermal conductivity $(0.052$ $\mathrm{W} / \mathrm{mK}$ ). In brief, the new alternative of palm-based PU utilizedasfillerand proposed in the concrete technology, specifically for lightweight concrete and insulated materials.

\section{References}

[1] Malaysia Palm Oil Board (MPOB). 2008. Palm-based polyols as natural oil polyols.

[2] K. H. Badri, 2012. Biobased polyurethane from palm kernel oil-based polyol, in: F. Zafar, E. Sharmin, Polyurethane, InTech Publishing, Croatia, 2012, pp.447-469.

[3] K. Ashida, Polyurethane and related foams: Chemistry and Technology, Taylor \& Francis,London, 2007.

[4] S. Hirose, K. Kobashigawa, H. Hayakeyama, Preparation and physical properties of polyurethane derives from molasses, Sen-I Gakkaishhi. 50(1994) 538-542.

[5] M. Sonnenschein, B.L. Wendt, A. K. Schrock, J. M. Sonney, A. J. Ryan, The relationship between polyurethane foam microstructure and foam aging, Polym. 49 (2008) 934-942.

[6] S. G. Gonzalez, J. Gadea, A. Rodroguez, C. Junco, V. Calderon, Lightweight plaster materials with enhanced thermal properties made with polyurethane foam wastes, Cons. Build. Mater. 28 (2012) 653-658.

[7] P. Mounanga, W. Gbongbon, P.Poullain, P.Turcry, Proportioning and characterization of lightweight concrete mixtures made with rigid polyurethane foam waste, Cem. Concr. Compos. 30 (2008) 806-814.

[8] V. Vaclavik, T. Dvorsky, V. Dimer, J. Daxner, J. Valicek, M. Harnicarova, M.Kusnerova, P. Kostial, M. Bendova, Recycling polyurethan efoam and its use as filler in renovation mortar with thermal insulating effect, in: J. M. P.Q. Delgado, Industrial and technological applications of transport in porous materials, Springer, Berlin, 2013, pp. 141-170. 
[9] K. H. Badri, MyIPO Malaysia Patent, MY 145094-A. (2012).

[10] G. Woods, The ICI polyurethane book, John Wiley \& Sons, New York, 1990.

[11] R. Tanaka, S. Hirose, H. Hatakeyama, Preparation and characterization of polyurethane foams using oil-based polyol, Biores. Tech. 99 (2008) 3810-3816.

[12] Yi Xu, L. Jiang, Investigating mix proportions of lightweight expanded polystyrene concrete, Appl. Mech. Mater. 71-78 (2011) 950-953.

[13] S. Akcaozoglu, K. Akcaaozoglu, C. D. Atis, thermal conductivity, compressive strength, ultrasonic wave velocity of cementitious containing waste PET lightweight aggregate, Comp.:Part B. 45(2013)721-726.

[14] M. Pfunstein, R. Gellert, M. H. Spitzner, A. Rudolphi, Insulating materials: Principles, Materials and Applications, first ed., Aumuller Druck, Switzerland, 2008. 